Supplement of

\title{
Characterization of submicron particles by time-of-flight aerosol chemical speciation monitor (ToF-ACSM) during wintertime: aerosol composition, sources, and chemical processes in Guangzhou, China
}

Junchen Guo et al.

Correspondence to: Shengzhen Zhou (zhoushzh3@mail.sysu.edu.cn) and Jun Zhao (zhaojun23@mail.sysu.edu.cn)

The copyright of individual parts of the supplement might differ from the CC BY 4.0 License. 
Table S1. Chemical composition of NR-PM 1 in the Pearl River Delta (PRD) region

\begin{tabular}{cccccccc}
\hline Location & time & NR-PM1 $\left(\mu \mathrm{g} \mathrm{m}^{-3}\right)$ & $\mathrm{OA}(\%)$ & $\mathrm{SO}_{4}^{2-}(\%)$ & $\mathrm{NO}_{3}^{-}(\%)$ & $\mathrm{NH}_{4}^{+}(\%)$ & $\mathrm{Cl}^{-}(\%)$ \\
\hline Panyu & winter.2014 & 55.4 & 50.5 & 25.2 & 12.2 & 9.9 & 2.1 \\
Shenzhen & winter.2009 & 44.5 & 46.2 & 28.5 & 11.6 & 11.9 & 1.9 \\
Kaiping & winter.2008 & 33.1 & 36.3 & 36.0 & 11.5 & 15.0 & 1.2 \\
Guuangzhou & winter.2017 & 35.3 & 49.0 & 20.0 & 17.0 & 13.0 & 1.0 \\
\hline
\end{tabular}

Table S2. OA compositions in the PRD region

\begin{tabular}{cccc}
\hline Location & time & OA $\left(\mu \mathrm{g} \mathrm{m}^{-3}\right)$ & OA compositions \\
\hline Panyu & Winter 2014 & 25.6 & HOA $(26 \%)$, COA (8\%), BBOA (4\%), SVOOA (32\%), LVOOA (29\%) \\
Shenzhen & Winter 2009 & 20.47 & HOA (29.5\%), BBOA (24.1\%), SVOOA (27.6\%), LVOOA (18.8\%) \\
Kaiping & Winter 2008 & 11.92 & BBOA (24.5\%), SVOOA (35.8\%), LVOOA (39.6\%) \\
Guangzhou & Winter 2017 & 17.3 & HOA (13\%), COA (18\%), SVOOA (30\%), LVOOA (40\%) \\
\hline
\end{tabular}

Table S3. P-value, T-value, number of points (n), and Pearson Correlations between SOA and RO2* for different NR-PM concentration intervals.

\begin{tabular}{ccccc}
\hline NR-PM $_{1}\left(\mu \mathrm{g} \mathrm{m}^{-3}\right)$ & $\mathrm{r}$ & $\mathrm{n}$ & $\mathrm{T}$ & $\mathrm{p}$ \\
\hline$<30$ & 0.31 & 47 & 5.07 & $<0.001$ \\
$30-40$ & 0.50 & 60 & 4.40 & $<0.001$ \\
$40-50$ & 0.53 & 35 & 3.56 & 0.0012 \\
$50-60$ & 0.49 & 41 & 3.51 & 0.0011 \\
$60-70$ & 0.62 & 40 & 4.93 & $<0.001$ \\
$>70$ & 0.59 & 30 & 3.85 & $<0.001$ \\
\hline
\end{tabular}


(a)

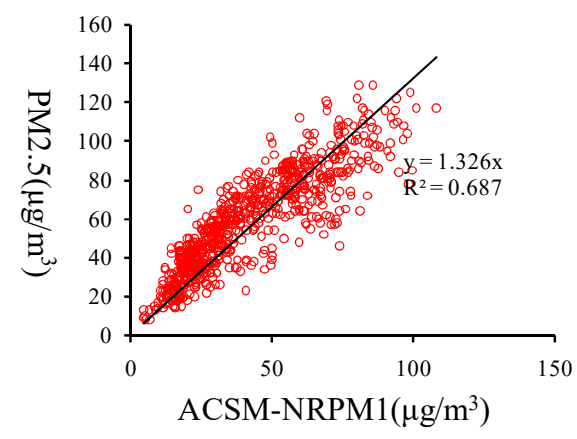

(c)
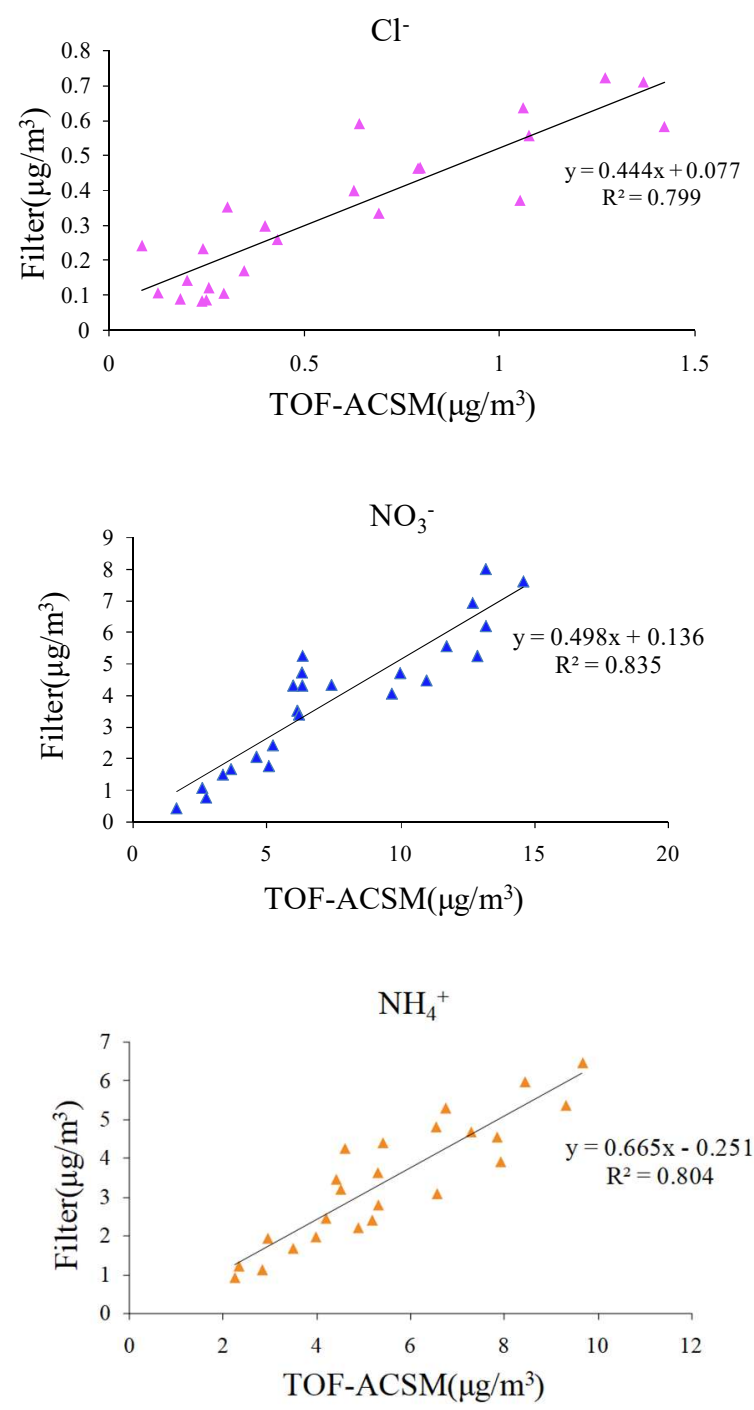

(b)
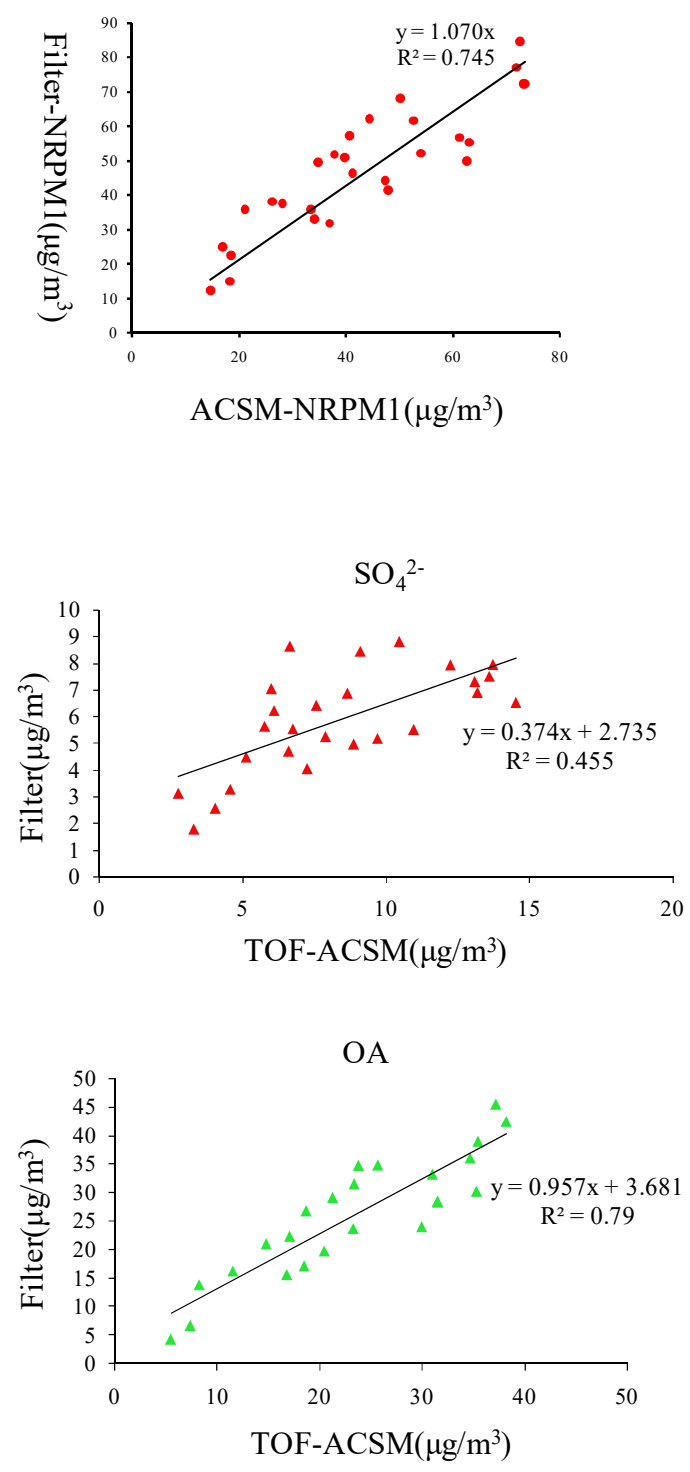

Figure S1. Comparisons between measurements by ToF-ACSM and those by BAM-1020 (PM 2.5$)$ and filter method: (a) NR$\mathrm{PM}_{1}$ mass concentration measured by ToF-ACSM vs. $\mathrm{PM}_{2.5}$ mass concentration measured by BAM-1020; (b) NR-PM concentration measured by ToF-ACSM vs. NR-PM 1 concentration based on filter (sum of sulfate, nitrate, ammonium, chloride

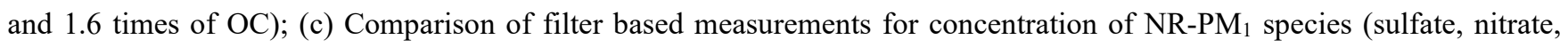
ammonium, chloride and OA) with the concentration of the corresponding NR-PM 1 components measured by ToF-ACSM. OA from filter data is calculated to be 1.6 times OC. 


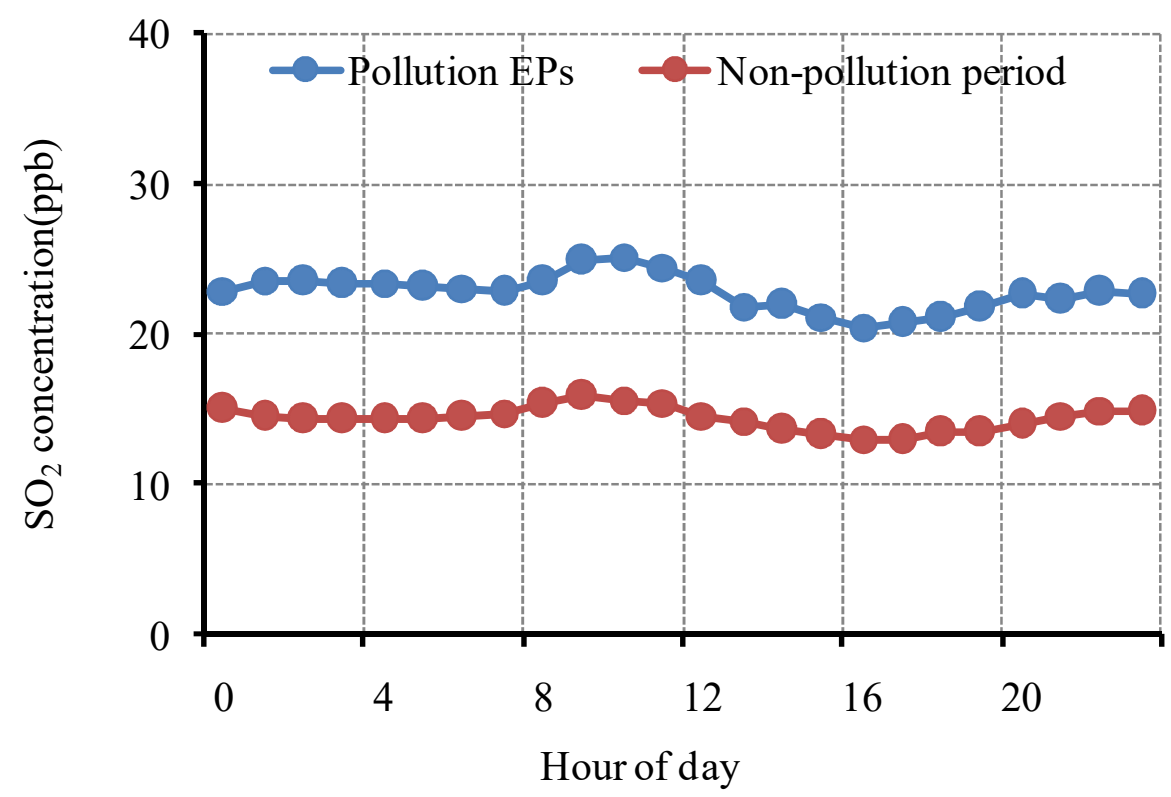

Figure S2. Diurnal profiles of $\mathrm{SO}_{2}$ concentration for non-pollution period (red line) and pollution EPs (blue line).

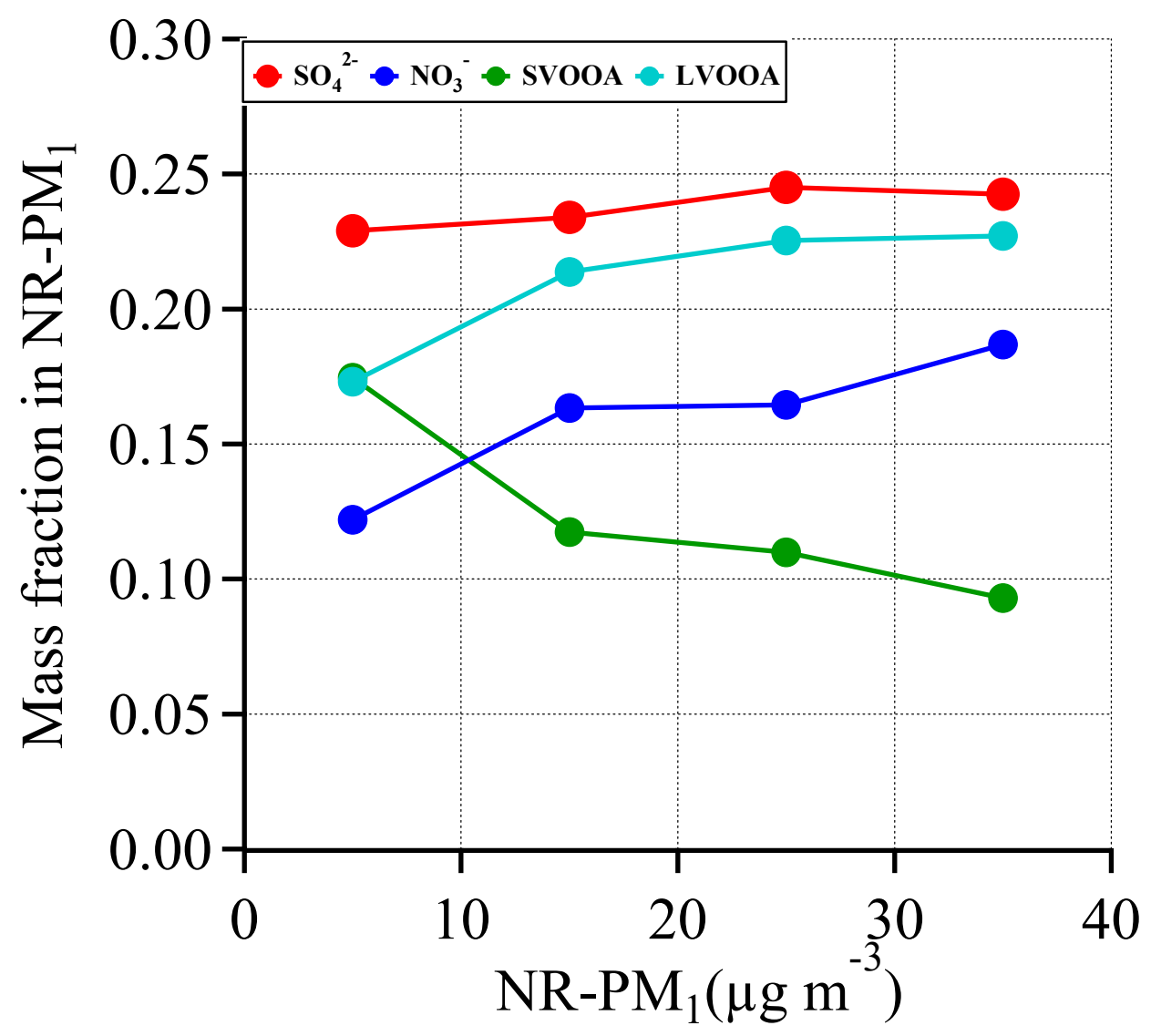

Figure S3. Evolution of SPM species fractions with concentration of NR-PM 1 for non-pollution period. 

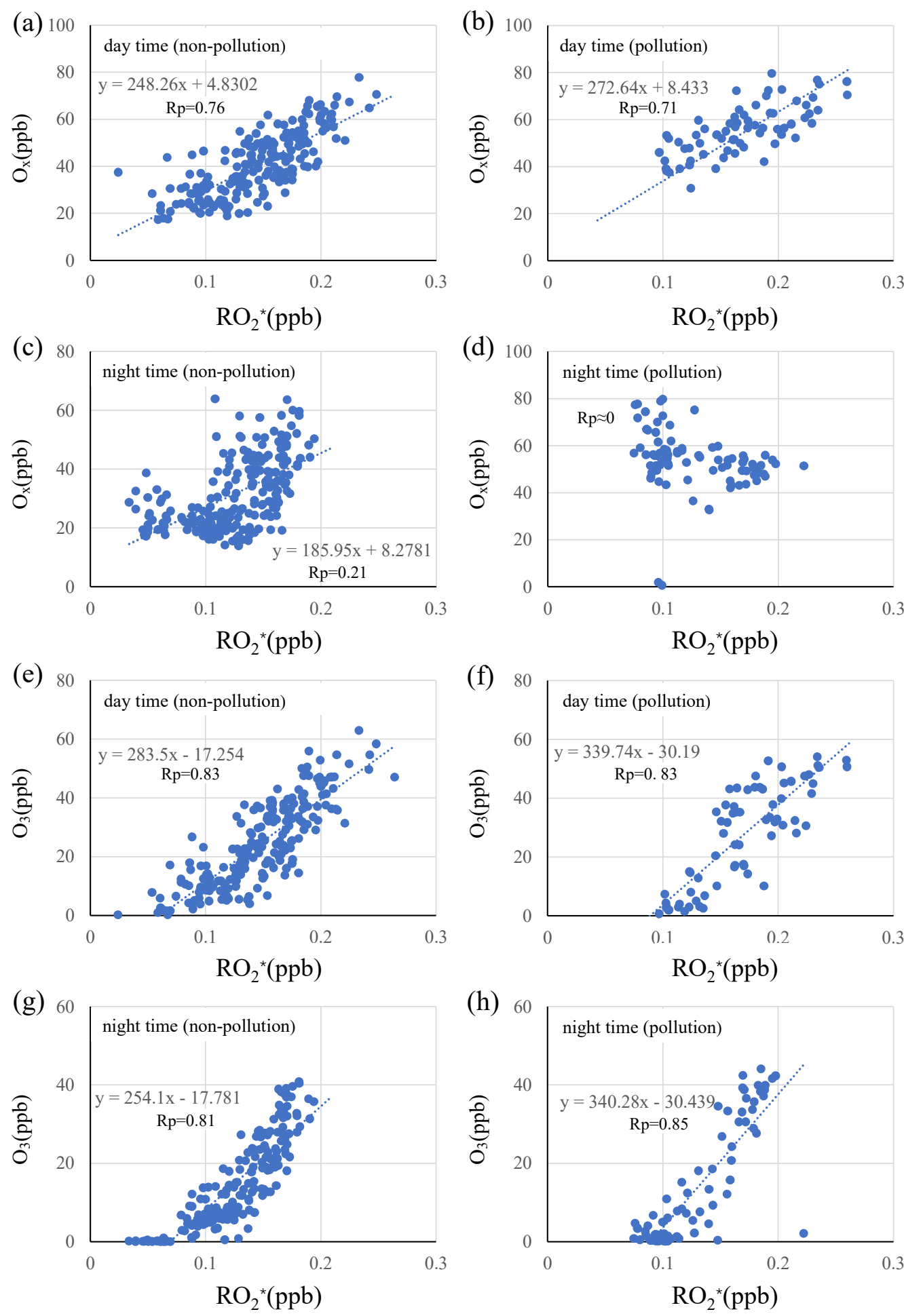

Figure S4. Dependence of $\mathrm{O}_{\mathrm{x}}$ and $\mathrm{O} 3$ on $\mathrm{RO}_{2} *$ for different scenarios (non-pollution daytime period, pollution daytime EPs, non-pollution nighttime period, and pollution nighttime EPs). All the regressions are orthogonally linear. 


\section{Methods}

OA components were deconvolved through an improved source apportionment technology called Multilinear Engine (ME-2) developed from Positive Matrix Factorization (PMF) and running on an igorbased interface (SoFi). Compared to traditional PMF, ME-2 offers a so-called a-value approach (Canonaco et al., 2013) using user defined external profiles or time series to constrain F (factor profile matrix) and $\mathrm{G}$ (concentration time series matrix) defined in model with a variable range (a value), which can be described as follows:

$$
\begin{aligned}
& f_{j, \text { solution }}=f_{j, \text { external }} \pm \mathrm{a} \cdot f_{j, \text { external }} \\
& g_{i, \text { solution }}=g_{i, \text { external }} \pm \mathrm{a} \cdot g_{i, \text { external }}
\end{aligned}
$$

10 where $f_{j}$ and $g_{i}$ represent row and column of the matrices $F$ and $G$, respectively. The index $j$ varies between 0 and the number of variables and $i$ varies between 0 and the number of measured points. Therefore, more efficient searches of solution space and a more objective choice of optimal solution are solved through the recently developed algorithm. Similar to many previous studies, ions with $\mathrm{m} / \mathrm{z}$ beyond 120 were removed from ME-2 input matrix due to obviously low signal-to-noise ratios. We firstly performed totally unconstrained runs (i.e., PMF), with a possible factor number in a range of 2-10. The optimal number of factors should be chosen based on the value of $\mathrm{Q} / \mathrm{Q}_{\text {expected, }}$, rationality of factor profile, and correlation between the time series of deconvolved factors and the corresponding external tracers (Ulbrich et al., 2009; Zhang et al., 2011). The value of $\mathrm{Q} / \mathrm{Q}_{\text {expected }}$ decreased with increase of factor number but this tendency was obviously damped for a factor number larger than 2 , which means factor number should be

20 larger than 2. However, we found that solutions with factor number $>=5$ showed over-split factors without an explicit physical meaning while 3 -factor solution was obviously mixed. Hence, it turned out that the 4-factor solution had relatively reasonable profiles and time series under a fully unconstrained condition. Although the unconstrained 4-factor solution was overall reasonable, defects existed from the uncertainty of measured data and traditional PMF algorithm. For instant, the diurnal time series of HOA and COA concentrations exhibited a slight mis-deconvolution which showed an extremely weak peak for $\mathrm{COA}$ and a fake peak for HOA at noon. In addition, the profile of HOA showed considerably smaller proportions of $f_{55}$ and $f_{57}$ than previous studies in both laboratory and field studies. Similar findings were reported in previous studies (Zhang et al., 2012; Qin et al., 2017). The a-value approach offers additional limits for rotational ambiguity through introducing user defined external factor profiles (Paatero et al., 2009; Cheng et al., 2013), which has been proven to be an efficient way to remedy these misdeconvolution from PMF (Qin et al., 2017). Thus, we further constrained one of four factors with a standard HOA profile derived from the average PMF-resolved HOA factors from measurements carried out in 15 megacities similar to Guangzhou (Ng et al., 2011) with an a-value chosen to be $0.3,0.5$ and 0.7 respectively to explore the improved solution. The results showed that an unreasonably high proportion of $\mathrm{m} / \mathrm{z} 44$ were presented in COA profiles for solutions with an a-value of 0.5 and 0.7 . We hence adopt 4 factors and an a-value of 0.3 as the optimal solution. The results from ME-2 are shown in Figures S5 S11, and Figures S16-S17. 


\section{$\underline{\text { PMF results }}$}
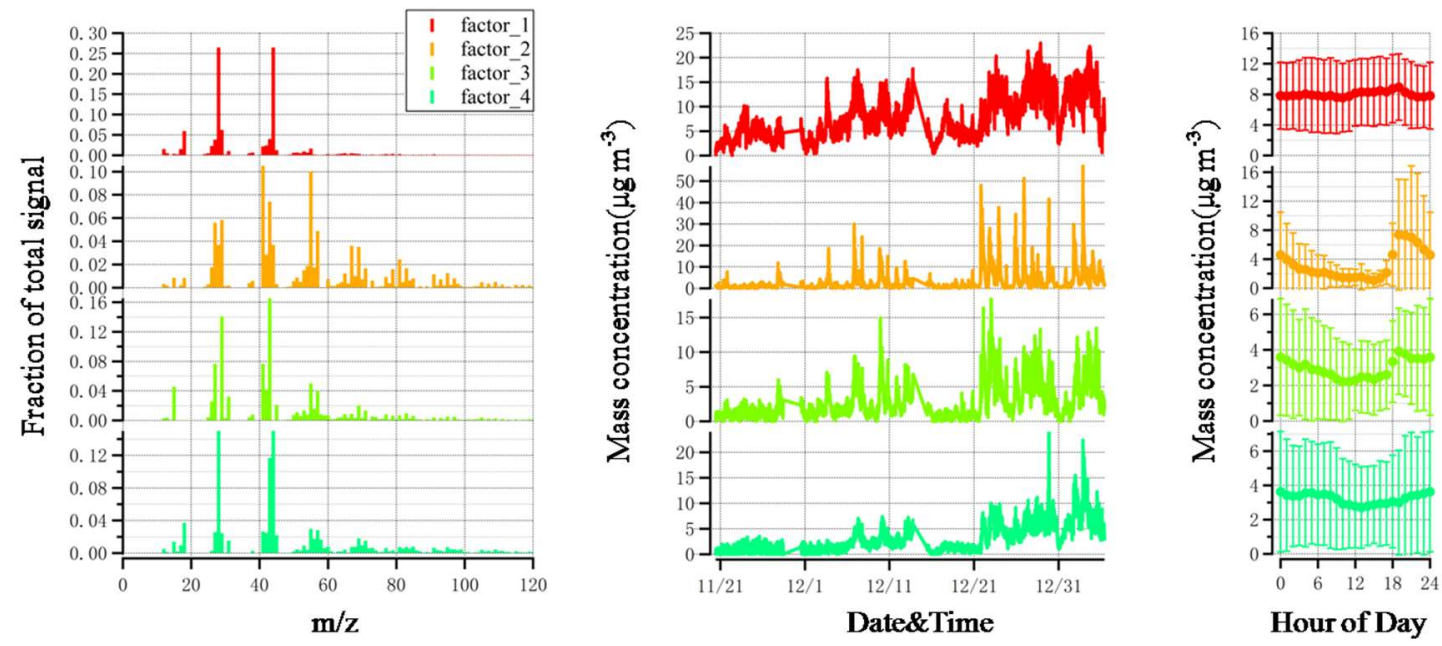

Figure S5. Results from the 4-factor solution of PMF.
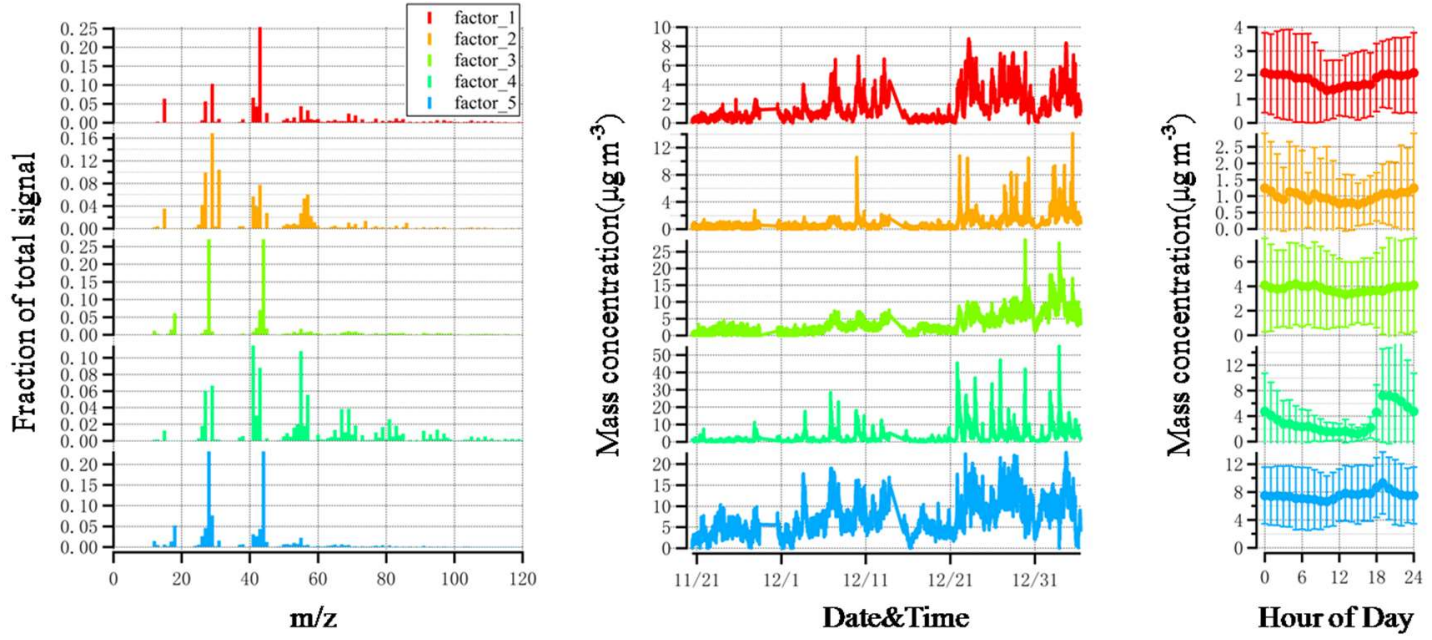

Figure S6. Results from the 5-factor solution of PMF.
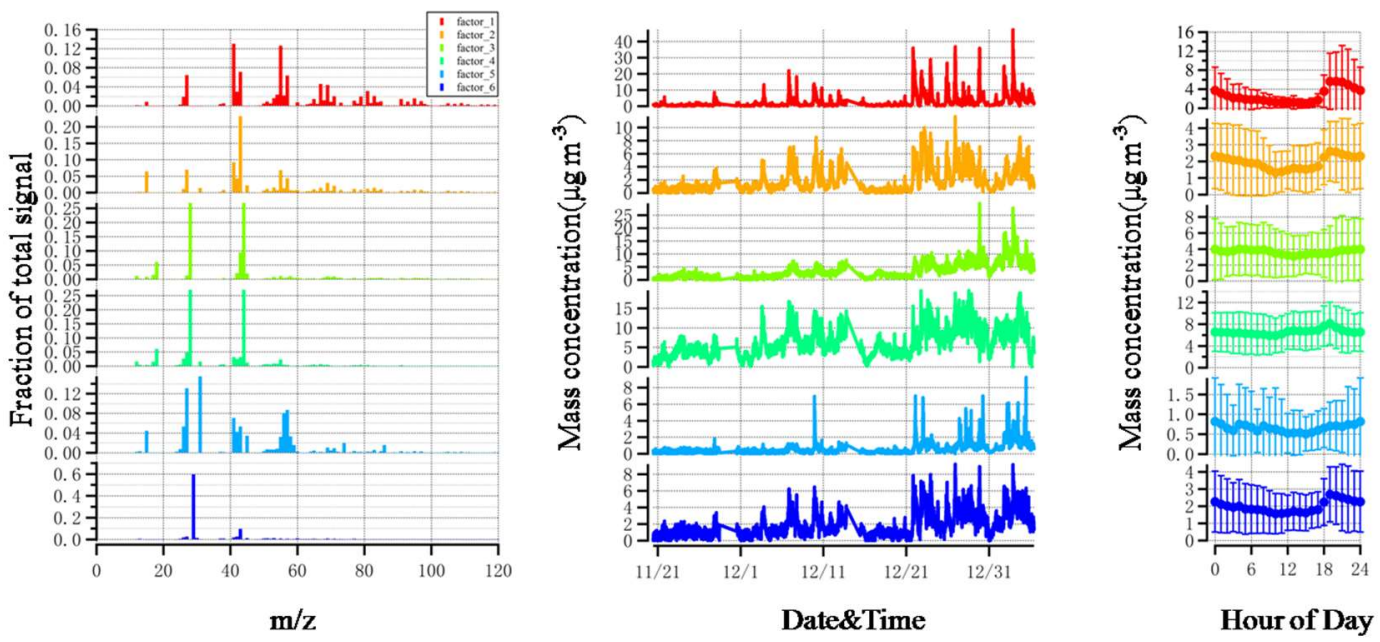

Figure S7. Results from the 6-factor solution of PMF. 


\section{a-value results (4 factors)}
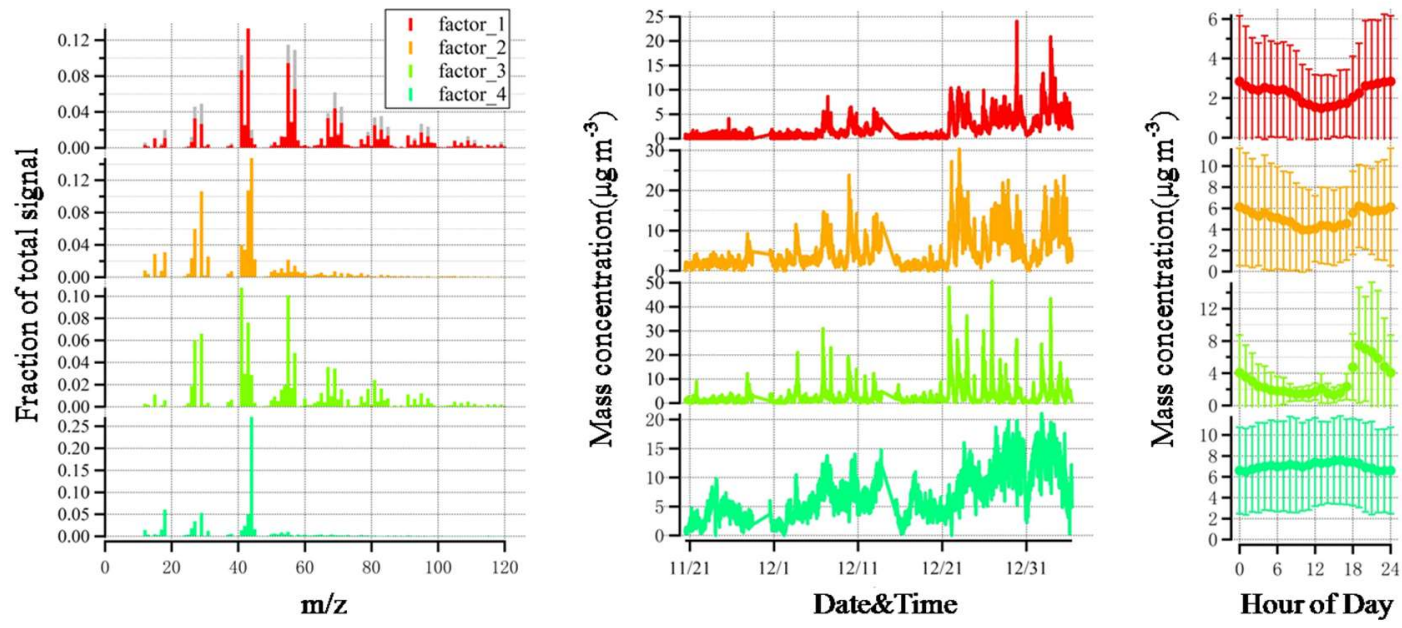

Figure S8. Results from the 4-factor solution with a-value $=0.3$. Gray bars represent standard HOA spectrum (Ng et al., 2011)
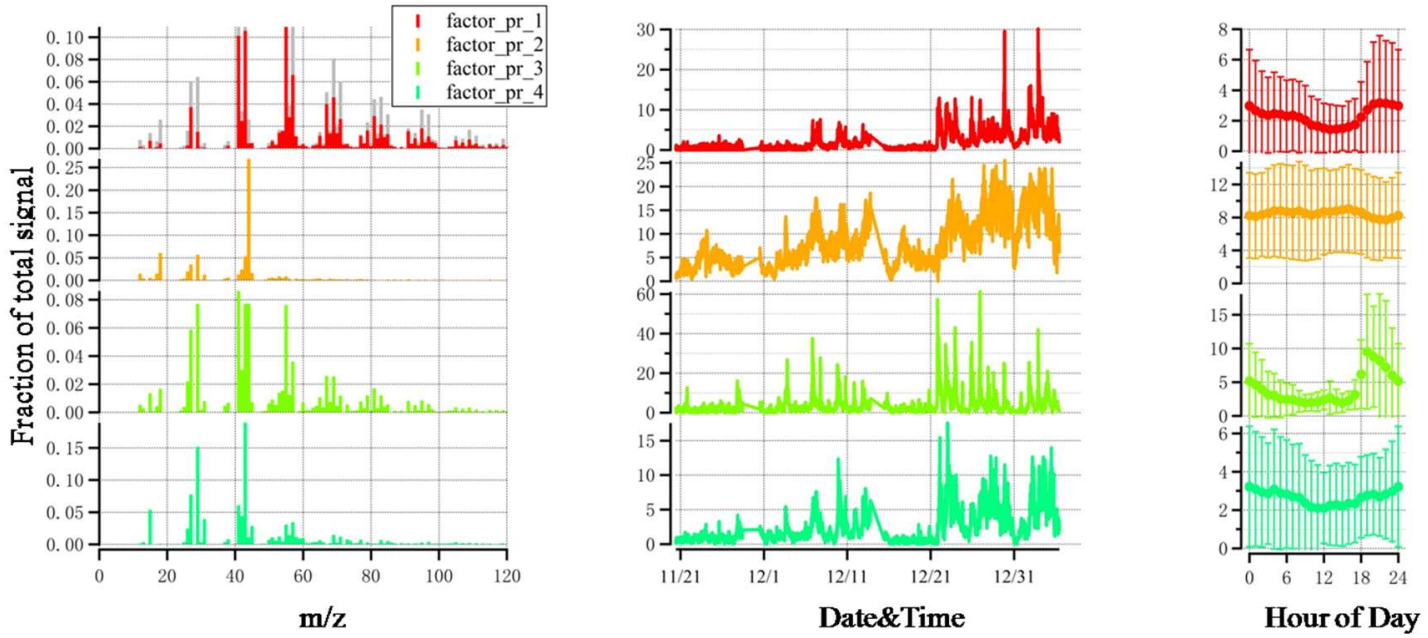

Figure S9. Results from the 4-factor solution with a-value $=0.5$. Gray bars represent standard HOA spectrum (Ng et al., 2011)
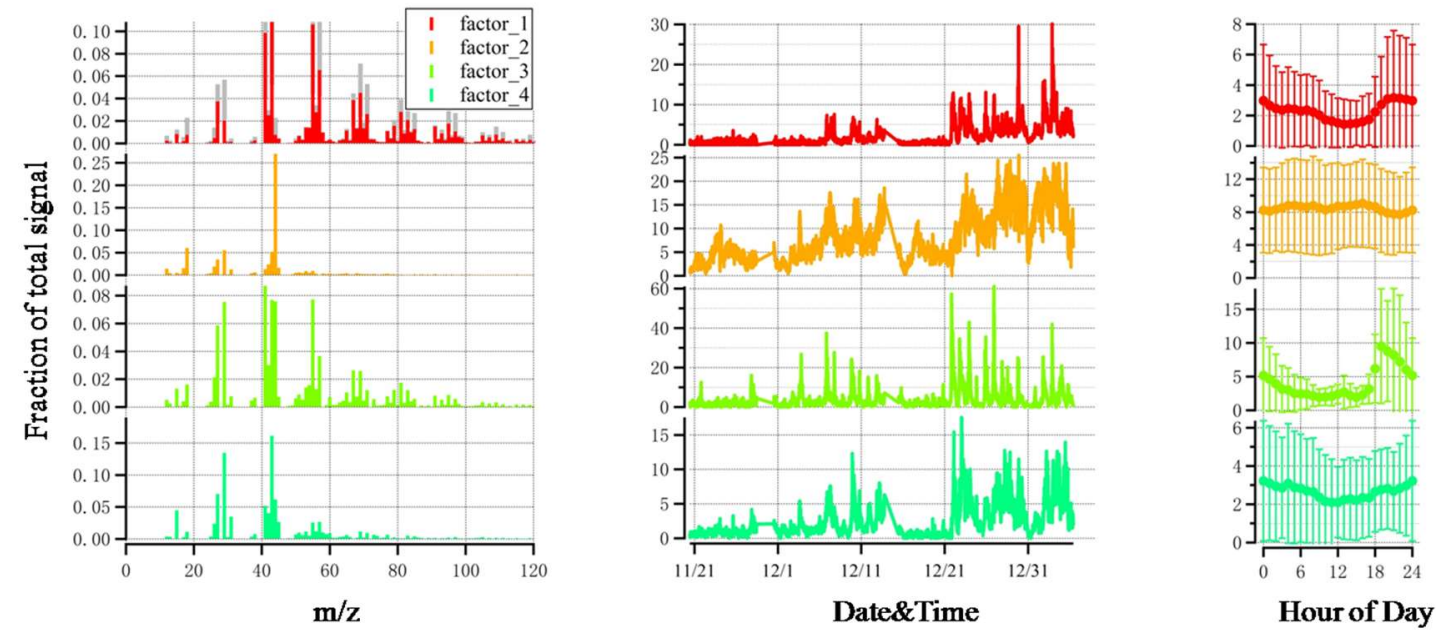

Figure S10. Results from the 4-factor solution with a-value $=0.7$. Gray bars represent standard HOA spectrum ( $\mathrm{Ng}$ et al., 2011) 

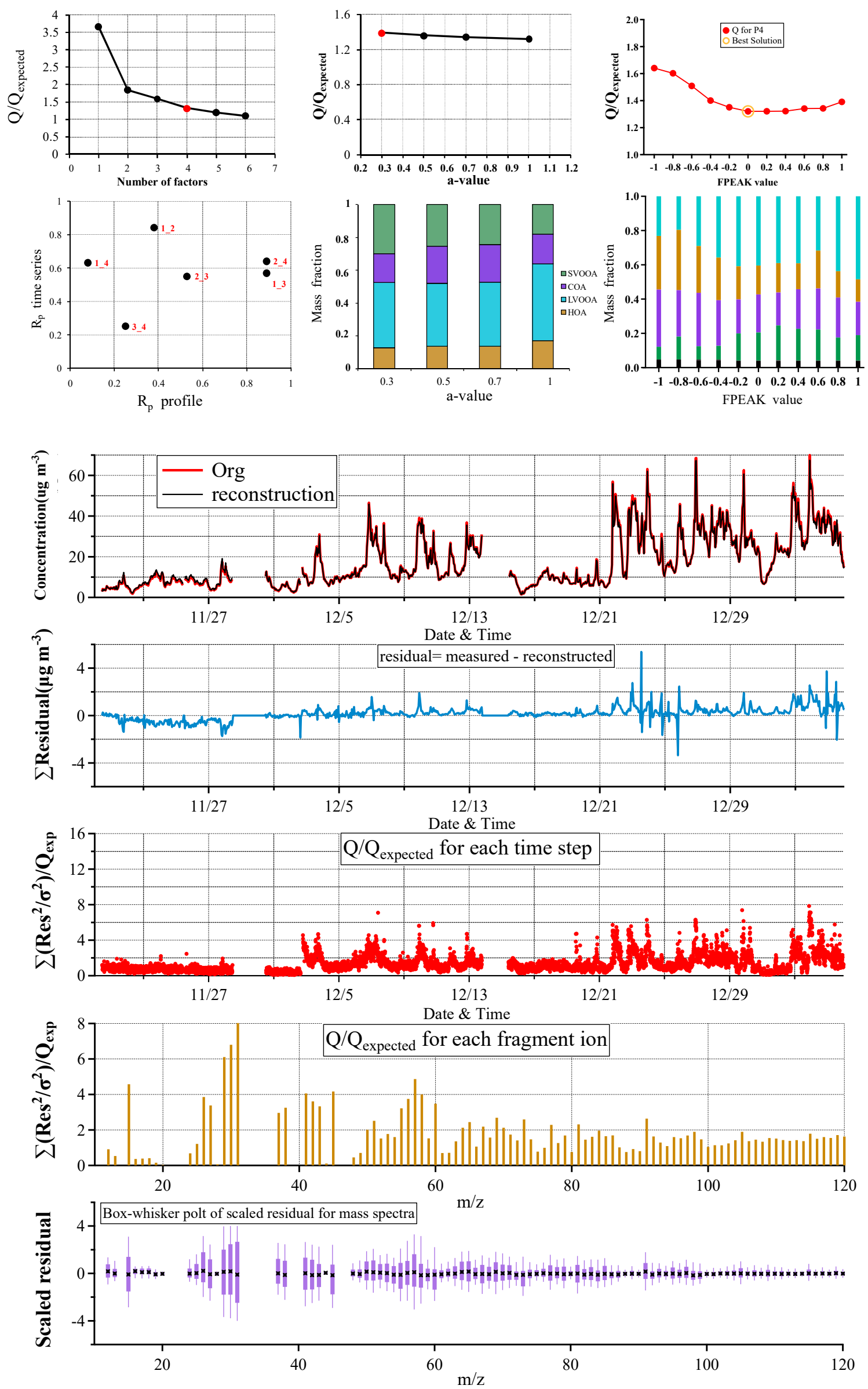

Figure S11. ME-2 diagnostics for the 4 factor solution with a-value=0.3 (the chosen optimal solution) 


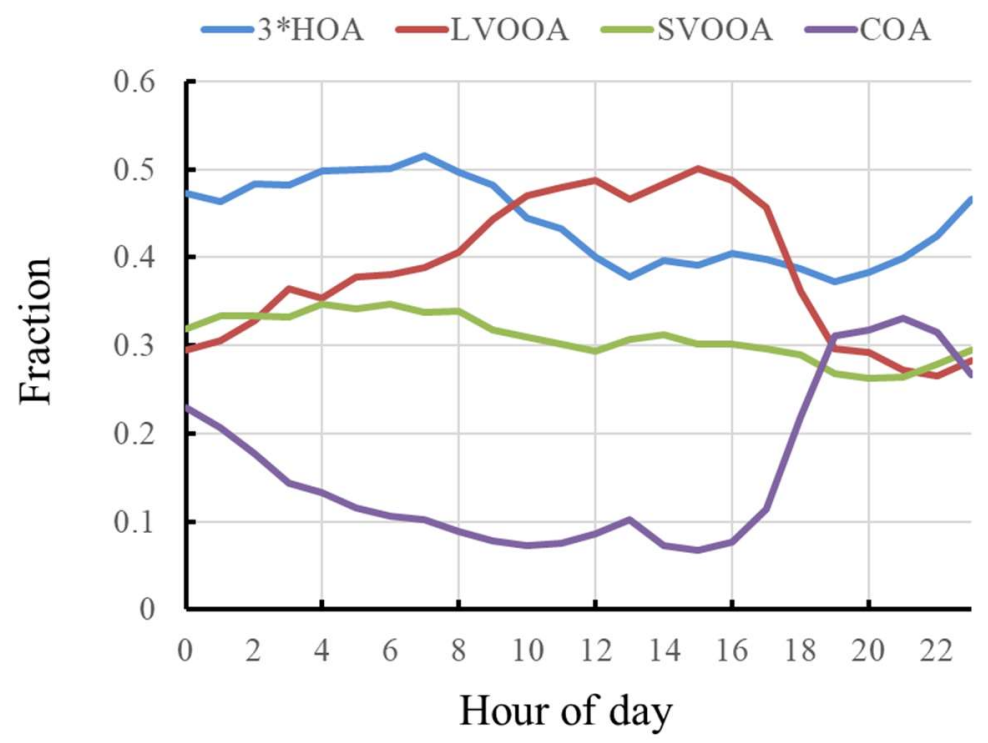

Figure S12. The diurnal fractions of 4 OA components for pollution EPs. 
0-2

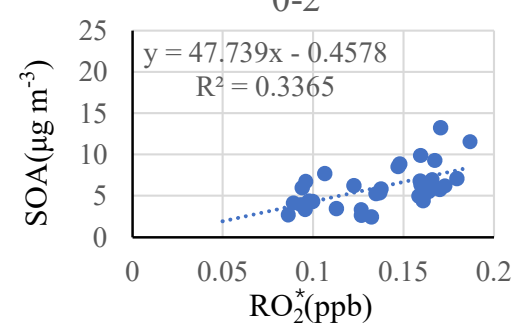

6-8

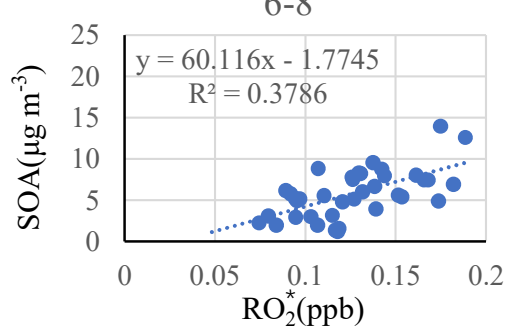

12-14

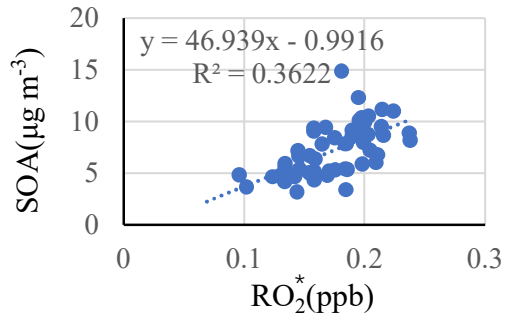

18-20

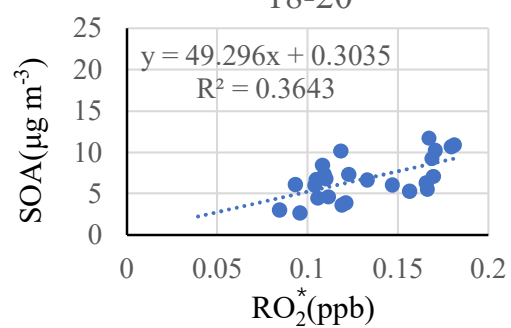

2-4

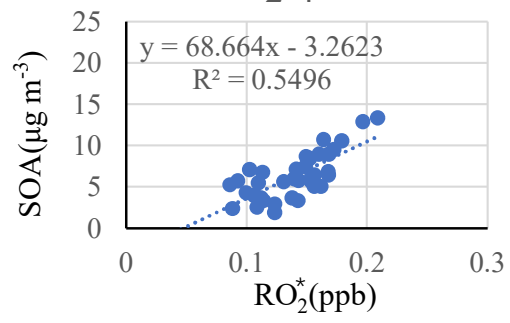

8-10

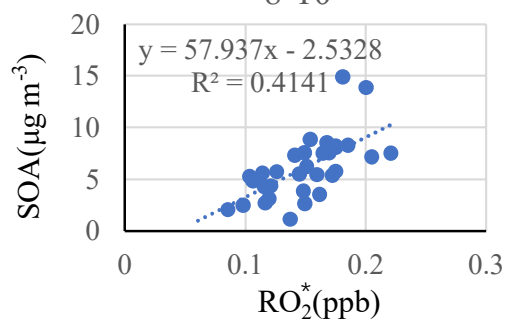

14-16

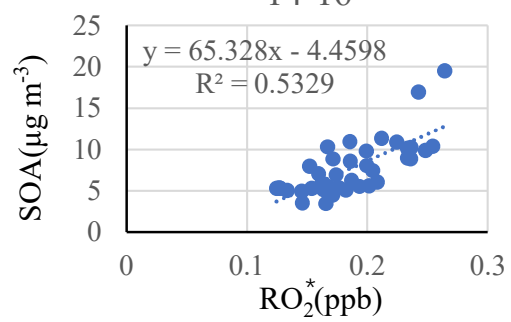

20-22

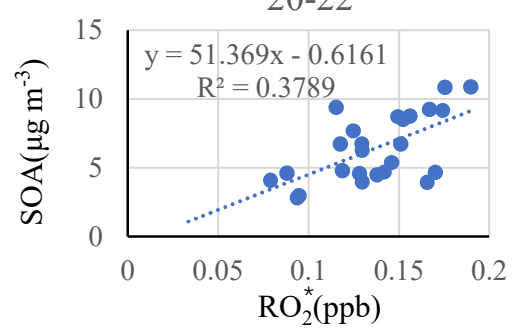

4-6

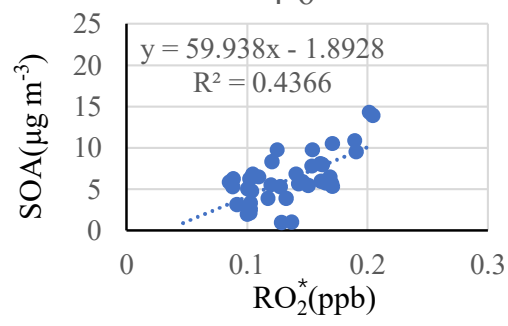

10-12

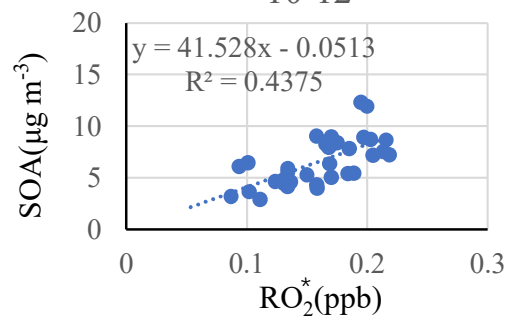

16-18

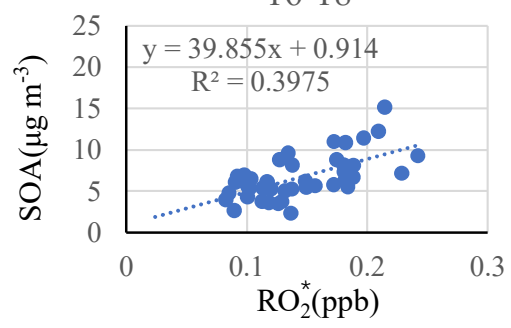

22-24

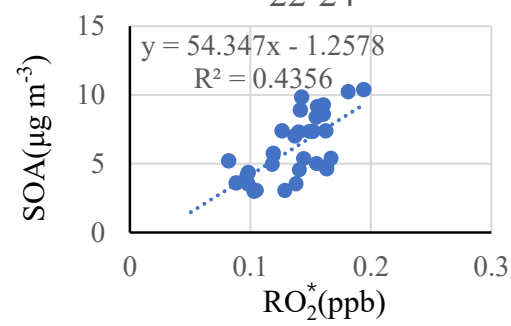

Figure S13. Dependence of $\mathrm{SOA}$ on $\mathrm{RO}_{2} *$ concentration for the same short period of every day (i.e., every 2 hours) during non-pollution periods. Note that all the correlations are statistically significant ( $p$ value $<0.01)$. 

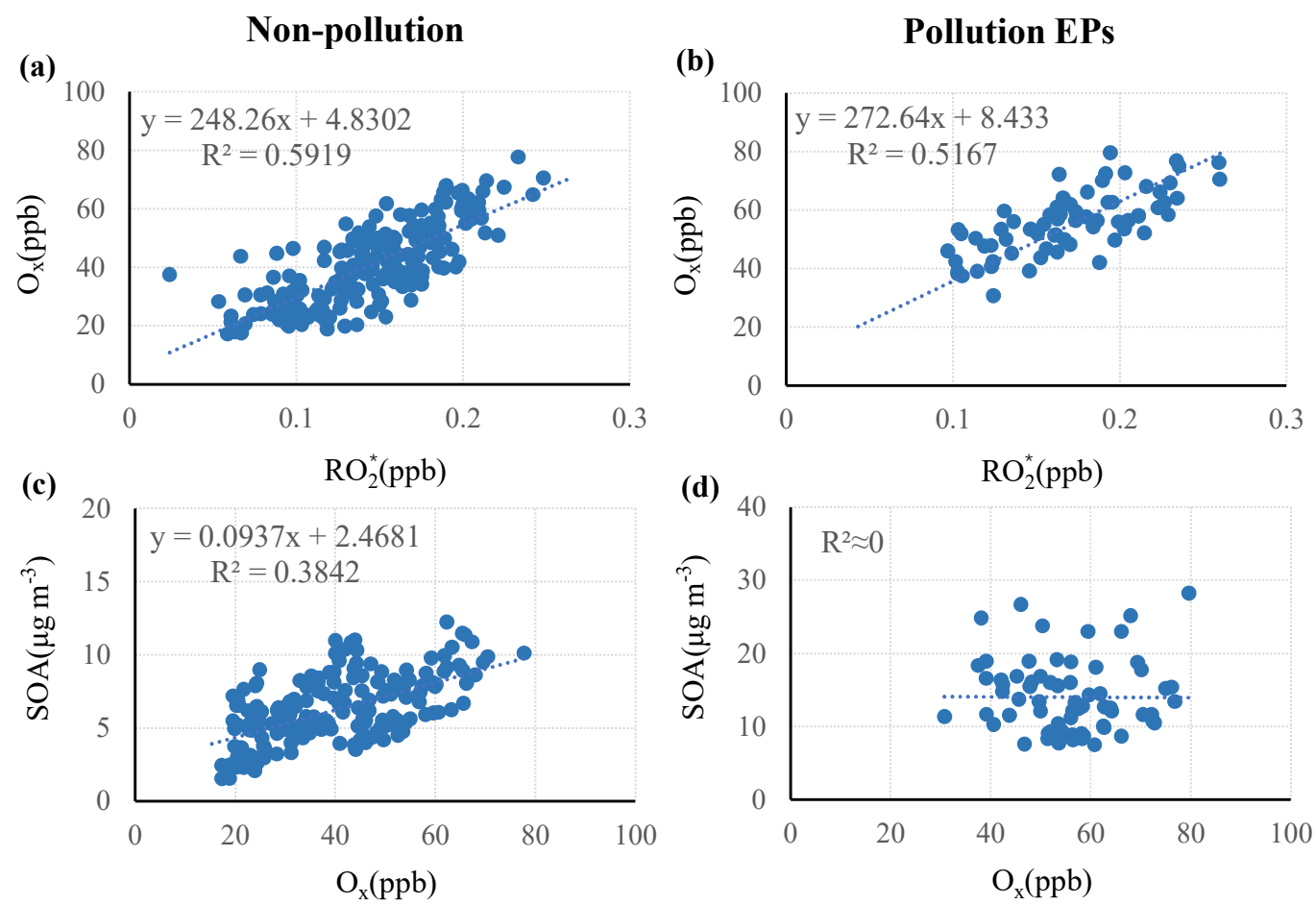

Figure S14. Daytime dependence of $\mathrm{O}_{\mathrm{x}}$ on $\mathrm{RO}_{2}{ }^{*}(\mathrm{a}, \mathrm{b})$ and dependence of SOA on $\mathrm{O}_{\mathrm{x}}(\mathrm{c}, \mathrm{d})$ for pollution EPs and non-pollution period.
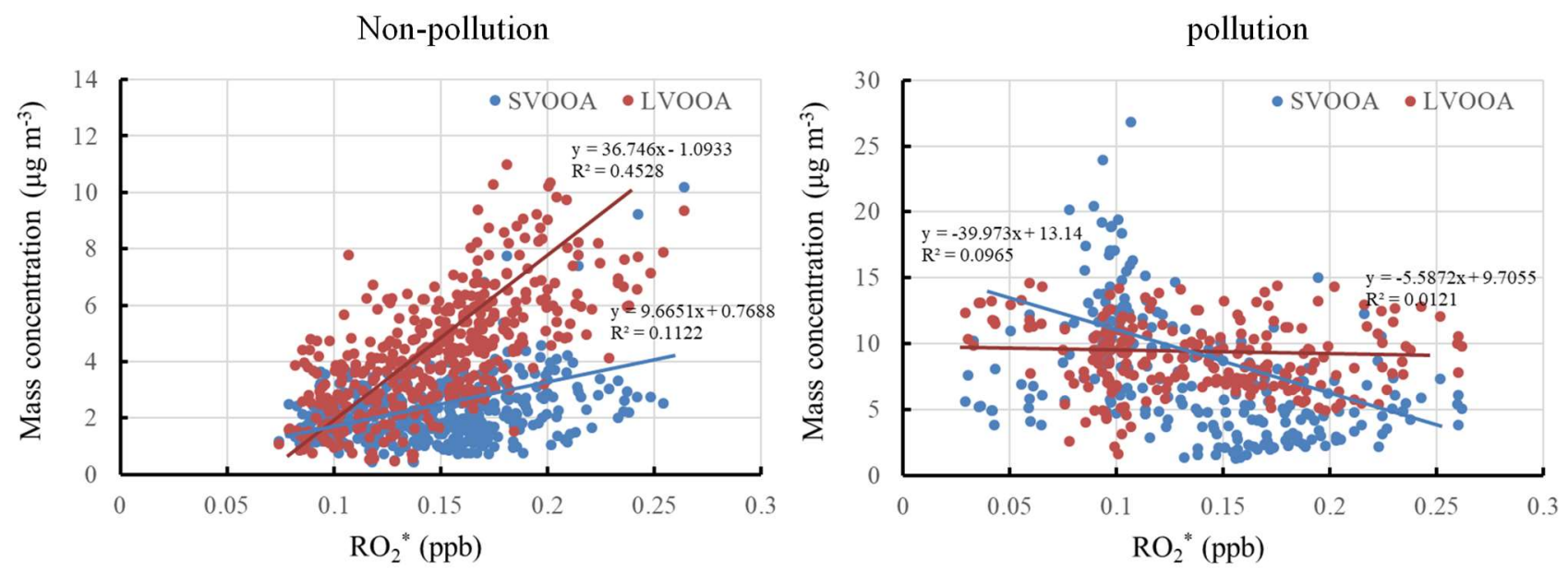

Figure S15. Scatter plots between $\mathrm{RO}_{2}{ }^{*}$ and SVOOA/LVOOA for non-pollution period and pollution EPs. 

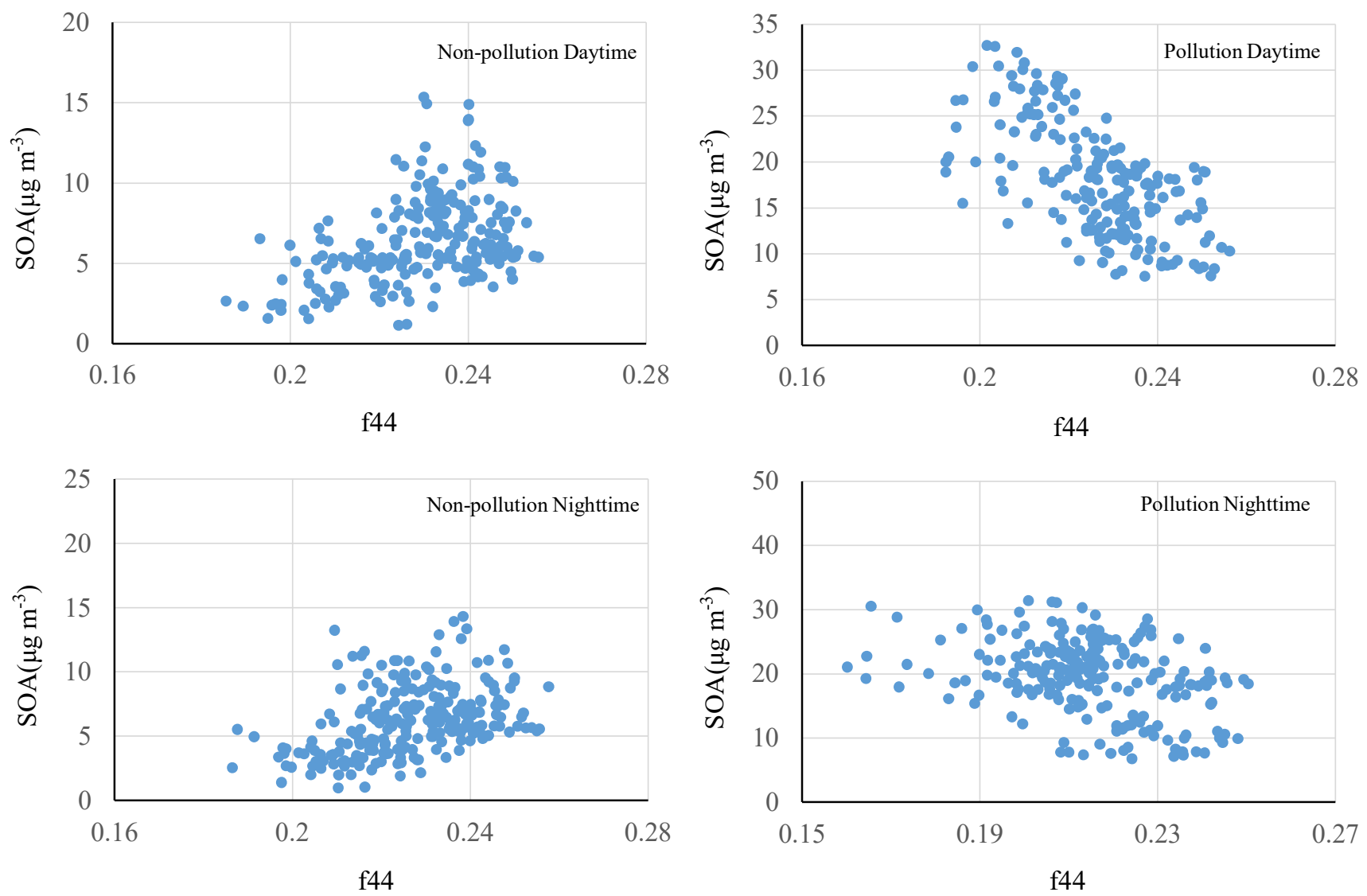

Figure S16. Scatter plots between SOA and $f_{44}$ for different scenarios (non-pollution daytime, nonpollution nighttime, pollution daytime and pollution night time).

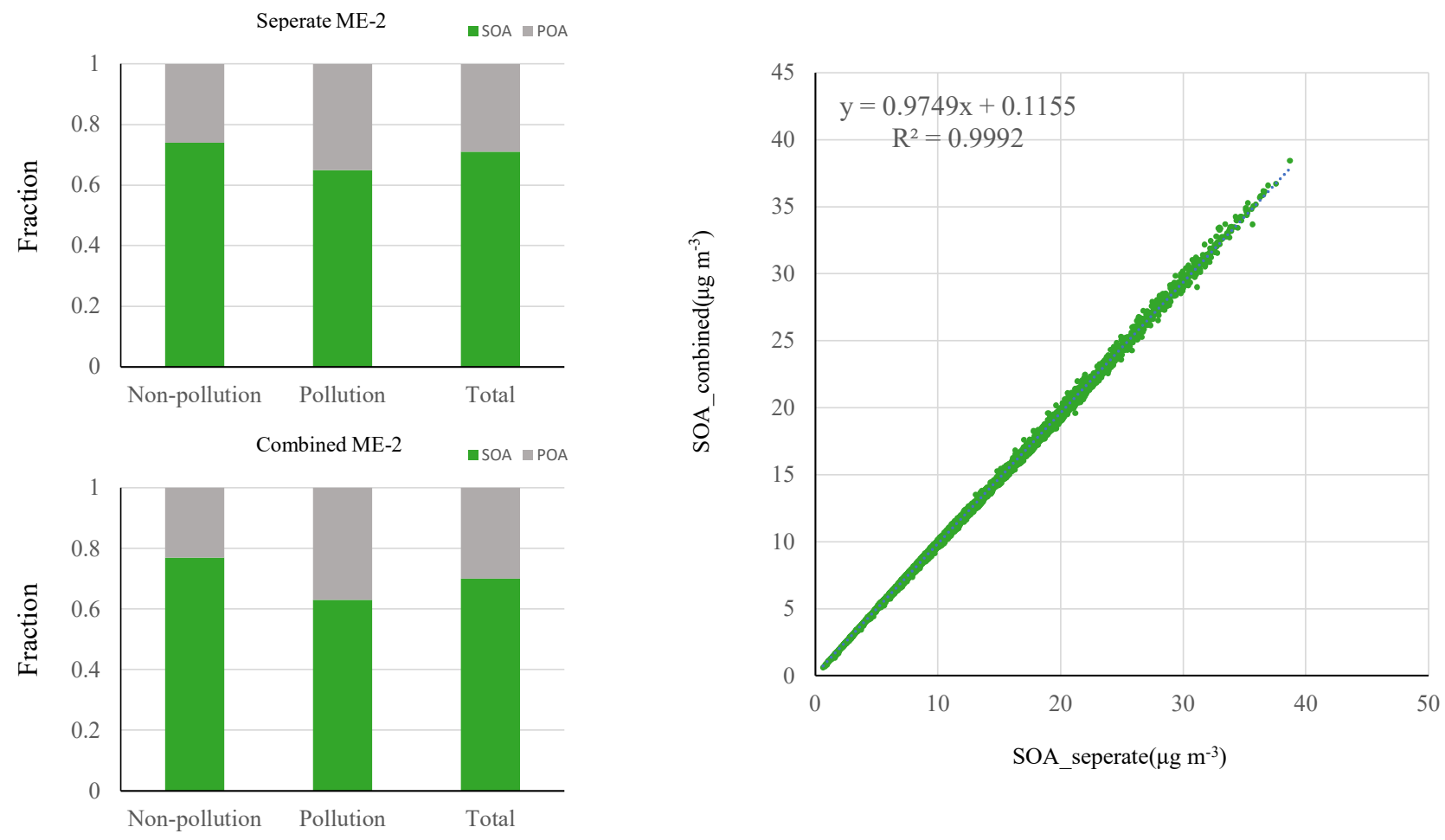

Figure S17. Comparison between combined ME-2 and separate ME-2, along with their correlation. 


\section{References}

Canonaco, F., Crippa, M., Slowik, J. G., Baltensperger, U., and Prévôt, A. S. H.: SoFi, an IGOR-based interface for the efficient use of the generalized multilinear engine (ME-2) for the source apportionment: ME-2 application to aerosol mass spectrometer data, Atmospheric Measurement Techniques, 6, 3649-3661, 10.5194/amt-6-3649-2013, 2013.

Cheng, Y., Engling, G., He, K. B., Duan, F. K., Ma, Y. L., Du, Z. Y., Liu, J. M., Zheng, M., and Weber, R. J.: Biomass burning contribution to Beijing aerosol, Atmospheric Chemistry and Physics, 13, 7765-7781, 10.5194/acp-13-7765-2013, 2013.

Ng, N. L., Canagaratna, M. R., Jimenez, J. L., Zhang, Q., Ulbrich, I. M., and Worsnop, D. R.: Real-Time Methods for Estimating Organic Component Mass Concentrations from Aerosol Mass Spectrometer Data, Environmental Science \& Technology, 45, 910-916, 10.1021/es102951k, 2011.

Paatero, P., and Hopke, P. K.: Rotational tools for factor analytic models, Journal of Chemometrics, 23, 91-100, 10.1002/cem.1197, 2009.

Qin, Y. M., Tan, H. B., Li, Y. J., Schurman, M. I., Li, F., Canonaco, F., Prévôt, A. S. H., and Chan, C. K.: Impacts of traffic emissions on atmospheric particulate nitrate and organics at a downwind site on the periphery of Guangzhou, China, Atmospheric Chemistry and Physics, 17, 10245-10258, 10.5194/acp-17-10245-2017, 2017.

Ulbrich, I. M., Canagaratna, M. R., Zhang, Q., Worsnop, D. R., and Jimenez, J. L.: Interpretation of organic components from Positive Matrix Factorization of aerosol mass spectrometric data, Atmos. Chem. Phys., 9, 2891-2918, 10.5194/acp-92891-2009, 2009.

Zhang, Q., Jimenez, J. L., Canagaratna, M. R., Ulbrich, I. M., Ng, N. L., Worsnop, D. R., and Sun, Y.: Understanding atmospheric organic aerosols via factor analysis of aerosol mass spectrometry: a review, Analytical and bioanalytical chemistry, 401, 3045-3067, 10.1007/s00216-011-5355-y, 2011.

Zhang, Y., Sun, J., Zhang, X., Shen, X., Wang, T., and Qin, M.: Seasonal characterization of components and size distributions for submicron aerosols in Beijing, Science China Earth Sciences, 56, 890-900, 10.1007/s11430-012-4515-z, 2012. 